\title{
BMJ Open Rationale and cross-sectional study design of the Research on Obesity and type 2 Diabetes among African Migrants: the RODAM study
}

\author{
Charles Agyemang, ${ }^{1}$ Erik Beune, ${ }^{1}$ Karlijn Meeks, ${ }^{1}$ Ellis Owusu-Dabo, ${ }^{2}$ \\ Peter Agyei-Baffour, ${ }^{2}$ Ama de-Graft Aikins, ${ }^{3}$ Francis Dodoo, ${ }^{3}$ Liam Smeeth, ${ }^{4}$ \\ Juliet Addo, ${ }^{4}$ Frank P Mockenhaupt, ${ }^{5}$ Stephen K Amoah, ${ }^{5}$ Matthias B Schulze, ${ }^{6}$ \\ Ina Danquah, ${ }^{6}$ Joachim Spranger, ${ }^{7}$ Mary Nicolaou, ${ }^{1}$ Kerstin Klipstein-Grobusch, ${ }^{8,9}$ \\ Tom Burr, ${ }^{10}$ Peter Henneman, ${ }^{11}$ Marcel M Mannens, ${ }^{11}$ Jan $\mathrm{P}$ van Straalen, ${ }^{12}$ \\ Silver Bahendeka, ${ }^{13}$ A H Zwinderman, ${ }^{14}$ Anton E Kunst, ${ }^{1}$ Karien Stronks ${ }^{1}$
}

To cite: Agyemang $\mathrm{C}$, Beune E, Meeks K, et al. Rationale and cross-sectional study design of the Research on Obesity and type 2 Diabetes among African Migrants: the RODAM study. BMJ Open 2014;4:e004877. doi:10.1136/bmjopen-2014004877

- Prepublication history for this paper is available online. To view these files please visit the journal online (http://dx.doi.org/10.1136/ bmjopen-2014-004877)

Received 17 January 2014 Revised 31 January 2014 Accepted 14 February 2014

\section{CrossMark}

For numbered affiliations see end of article.

Correspondence to Dr Charles Agyemang; C.o.agyemang@amc.uva.nl

\section{ABSTRACT}

Introduction: Obesity and type 2 diabetes (T2D) are highly prevalent among African migrants compared with European descent populations. The underlying reasons still remain a puzzle. Gene-environmental interaction is now seen as a potential plausible factor contributing to the high prevalence of obesity and T2D, but has not yet been investigated. The overall aim of the Research on Obesity and Diabetes among African Migrants (RODAM) project is to understand the reasons for the high prevalence of obesity and T2D among sub-Saharan Africans in diaspora by (1) studying the complex interplay between environment (eg, lifestyle), healthcare, biochemical and (epi)genetic factors, and their relative contributions to the high prevalence of obesity and T2D; (2) to identify specific risk factors within these broad categories to guide intervention programmes and (3) to provide a basic knowledge for improving diagnosis and treatment. Methods and analysis: RODAM is a multicentre cross-sectional study among homogenous subSaharan African participants (ie, Ghanaians) aged $>25$ years living in rural and urban Ghana, the Netherlands, Germany and the UK (http://rod-am.eu/). Standardised data on the main outcomes, genetic and non-genetic factors are collected in all locations. The aim is to recruit 6250 individuals comprising five subgroups of 1250 individuals from each site. In Ghana, Kumasi and Obuasi (urban stratum) and villages in the Ashanti region (rural stratum) are served as recruitment sites. In Europe, Ghanaian migrants are selected through the municipality or Ghanaian organisations registers.

Ethics and dissemination: Ethical approval has been obtained in all sites. This paper gives an overview of the rationale, conceptual framework and methods of the study. The differences across locations will allow us to gain insight into genetic and non-genetic factors contributing to the occurrence of obesity and T2D and will inform targeted intervention and prevention programmes, and provide the basis for improving diagnosis and treatment in these populations and beyond.

\section{INTRODUCTION}

Ethnic minority and migrant populations in Europe have been disproportionately affected by obesity and diabetes compared with the host European origin populations (henceforth, Europeans). ${ }^{1-4}$ The prevalence of type 2 diabetes (T2D) in these populations, for example, is about three to five times higher than in Europeans. ${ }^{4}$ They also develop T2D at a younger age; and they have higher morbidity and mortality from T2D and related complications such as cardiovascular disease (CVD) than European populations. ${ }^{4} 5$ The little available information suggests that sub-Saharan Africa (SSA) migrants are particularly affected by obesity and T2D. ${ }^{3}$ In the Health Survey for England (HSE) 2004, the prevalence rates of T2D were $16.2 \%$ and $6 \%$ in SSA men and women aged $\geq 35$ years compared with $5.1 \%$ and $2.4 \%$ in English general population men and women, respectively. ${ }^{6}$

Obesity and T2D prevalence rates are not only escalating among SSA migrants, but also in their home countries. The increasing levels of obesity and T2D in SSA countries have been unprecedented and pose huge challenges for many countries. While T2D seemed to be virtually absent, for example, in West Africa in the $1960 \mathrm{~s}$ and $1980 \mathrm{~s}(0.2-1.7 \%)$, today it has become a major health problem affecting almost $7 \%$ of the adult population. ${ }^{7-10}$ Projections indicate that the number of T2D 
patients in SSA will double from 14.7 million in 2011 to 28 million in $2020,{ }^{11}$ undoubtedly among one of the highest growth rates of T2D worldwide. ${ }^{11} 12$ This correlates with the simultaneous increase of obesity in the same region. ${ }^{7}$ A systematic review found that the prevalence of obesity in urban West Africa has more than doubled over the past 15 years. ${ }^{9}$ The serious cardiovascular complications of obesity and T2D could overwhelm SSA countries that are already straining under the burden of communicable diseases.

The reasons for the increased susceptibility of ethnic minority groups and migrants to obesity and T2D are poorly understood. Increased T2D prevalence and complications in African populations in SSA and industrialised countries have been attributed to delayed diagnosis and poor management due to low socioeconomic status. However, ethnic differences persist even when demographic, socioeconomic status, behavioural and clinical parameters have been taken into account, ${ }^{13}$ suggesting that other factors such as genetic predispositions might be important. The validity of this finding, nonetheless, is limited because of the heterogeneity of migrants studied so far. Heritability estimates for T2D range up to $40 \%,{ }^{14}{ }^{15}$ but genetic variations thus far identified contribute only a small fraction of the inherited risk. ${ }^{16}$ While genetic factors alone cannot explain the increasing prevalence of obesity and T2D, it is clear that the high prevalence of obesity and T2D is a result of a complex interplay of environmental and genetic factors that are likely to vary in different settings and among different population groups. Genetic predispositions and interactions between environmental and genetic factors may be involved in the onset and development of diseases such as obesity and T2D among migrant populations. The 'thrifty genotype' and 'thrifty phenotype' hypotheses are considered to be the underlying mechanism of the gene-environment interaction contribution to disease susceptibility. ${ }^{17-21}$ While gene-environment interactions may play an important role in disease susceptibility, research in this area, particularly within the context of human migration, is in its infancy.

The high levels of obesity and T2D among migrant populations may also be influenced by lifestyle changes following migration ${ }^{3}$ as well as psychological stress. ${ }^{22}$ Evidence from cohort studies demonstrate the importance of lifestyle factors such as physical inactivity and smoking on obesity and T2D. ${ }^{23-27}$ However, among migrant populations, interventions to reduce obesity and T2D have often been ineffective, ${ }^{28}$ and efforts often fail to meet the specific needs of ethnic minority and migrant populations. ${ }^{29}$ The local circumstances of ethnic minority and migrant populations, such as socioeconomic development of the groups, race relations and access to healthcare and preventive services, may differ greatly among industrialised countries. ${ }^{30} 31$ These differential contexts can influence health behaviour, psychosocial stress and healthcare use among ethnic minority and migrant groups, and subsequently lead to differences in CVD health outcomes between similar populations living in different countries.

The Research on Obesity and Diabetes among African Migrants (RODAM) project-an European Commission funded project-aims to understand the reasons for the high prevalence of obesity and T2D among African migrants by (1) studying the complex interplay between environmental exposures and genetics and their relative contributions to the high prevalence of obesity and T2D; (2) to identify specific risk factors within these broad categories to guide intervention programmes and (3) to provide a basic knowledge for improving diagnosis and treatment. A conceptual model of the RODAM project is presented in figure $1 .^{32}$ It shows that following migration, migrants may be exposed to varied contexts, such as different opportunities for socioeconomic development, different availability of food supply, different health systems and policies and different cultural traditions; and these differences may influence their health behaviour, physical and psychosocial stress and subsequently lead to differences in obesity and T2D risks.

\section{METHODS}

To achieve RODAM study goals, a multidisciplinary consortium of researchers from Europe (University of Amsterdam, Utrecht University, London School of Hygiene and Tropical Medicine, CharitéUniversitätsmedizin Berlin, German Institute of Human Nutrition) and Africa (University of Ghana, Kwame Nkrumah University of Science and Technology and the International Diabetes Federation (IDF), African region) with broad experience on chronic diseases in Africans and African migrants have joined forces. As a central feature of the RODAM project, at all study sites, highly standardised protocols of quantitative and qualitative assessments are applied for participant recruitment and topic-related investigations.

\section{Study population}

Assessing the role of gene-environmental interactions in risk factors, such as obesity and T2D, among migrant populations requires a highly standardised approach and relatively homogeneous migrating and nonmigrating populations. For this reason, we concentrate on a relatively homogenous SSA migrant population to enable comparisons of the prevalence of obesity and T2D between SSA migrants living in different European countries and their compatriots living in rural and urban SSA as outlined in the WHO Global Consultation on Migrant Health report. ${ }^{33}$ Consequently, adult Ghanaians (aged $\geq 25$ years) are recruited in rural and urban Ghana, and in the cities of Amsterdam, Berlin and London. Ghanaians are one of the largest SSA migrant groups in Europe. ${ }^{34-36}$ The 2009 estimates by the Office for National Statistics recorded 93000 Ghanaian-born people living in the UK. The majority of Ghanaians in the UK are concentrated in London boroughs of 


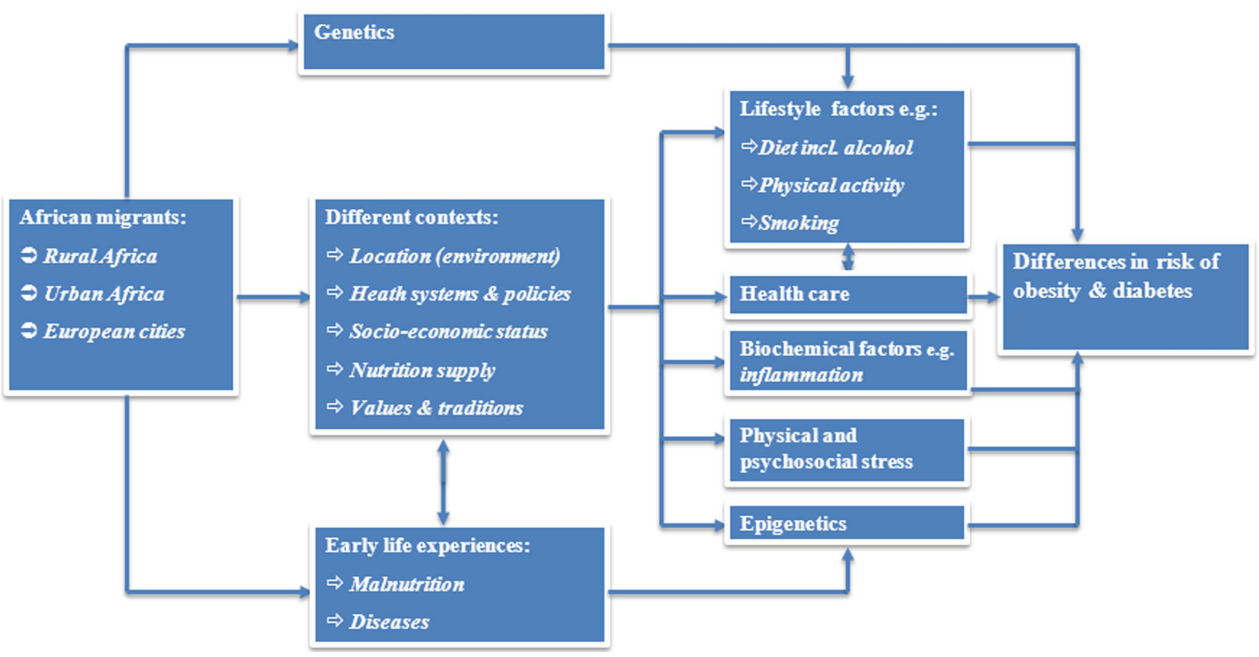

Figure 1 A conceptual model for the RODAM project.

Southwark, Lambeth, Newham, Hackney, Haringey, Lewisham, Croydon, Merton and Brent. ${ }^{34}$ In Germany, 22000 people are officially registered as Ghanaians, the majority of whom are concentrated in Berlin, Hamburg and North-Rhine Westphalia. ${ }^{35}$ In the Netherlands, in 2009, there were approximately 20000 officially recorded Ghanaians. The majority of these are concentrated in southeast Amsterdam. ${ }^{36}$

\section{Recruitment of the study participants \\ Engagement of Ghanaian community}

Previous work in the Netherlands and a feasibility study among African communities in the UK show that involvement of the community leaders enhances study participation and may help prevent a low response rate relating to language barriers and lack of understanding about the relevance of the study. ${ }^{37}$ The RODAM project, therefore, involves the Ghanaian community leaders in all sites. This includes working with religious communities (eg, churches and mosques), endorsement from local key figures and establishing relationships with healthcare organisations that serve these groups. In addition, the project team provides information about the study via local media aim at the Ghanaian population (eg, Ghanaian radio and TV stations).

Owing to differences in the population registration systems across European countries as well as in Ghana, different approaches are needed for the recruitment of the study populations across different locations. For example, there is a population register in the Netherlands where the Ghanaian migrants could be identified and randomly selected for the study. In Ghana, the UK and Germany, the situation is quite different as there are no population registers that will allow for the easy identification of these populations. It is important, however, to adopt the recruitment strategies that are comparatively as similar as possible across different locations. We describe below the various recruitment strategies in each site.

\section{Recruitment strategy in Ghana}

In Ghana, two cities (Kumasi and Obuasi) and 15 villages in the Ashanti region are served as the urban and rural recruitment sites. The initial sampling frame was the list of enumeration areas (EAs) in the Ashanti region from the 2010 census. A multistage random sampling procedure was adopted to arrive at the sampling of 30 EAs. EAs were stratified, weighted and a random sample of rural and urban EAs was selected. There are over 2000 urban EAs and more than 1000 rural EAs. The first stage was to group the districts into two main categories: districts with a high number of urban (Kumasi and Obuasi) areas and districts with a high number of rural EAs. The next stage of sampling was to put the EAs together in each of the categories and take a weighted random sample of 10 for Kumasi and 5 for Obuasi, respectively. The procedure was repeated for the rural EAs by adding all the EAs in the selected districts and weighted from the first stage together after which a simple random sample procedure was adopted to select the total number of rural EAs (15) required for the study. Letters are sent to all selected health and community authorities to notify them of the start of the study. We send team members to the various communities to stay among them. Once within the community, the team then organise mini clinics in the field for a period of 1-2 weeks depending on the sampled population and responsiveness of respondents.

\section{Recruitment strategy in the Netherlands}

In the Netherlands, Ghanaian participants were randomly drawn from Amsterdam Municipal Health register. This register contains data on country of birth of citizens and their parents, thus allowing for sampling based on the Dutch standard indicator for ethnic origin. All selected participants aged $\geq 25$ years were sent a written invitation combined with written information regarding the study and a opting out response card. Participants are reminded by phone or home visit after 
2 weeks if there is no response. After a positive response, an appointment for physical examination at a local health centre is made over the phone followed by a confirmation letter of the appointment, and a digital or paper version of the questionnaire (depending on the preference of the participant) is sent to the participant's home address.

\section{Recruitment strategy in the UK}

The UK has no population register for migrant groups. Consequently, Ghanaian organisations are served as the sampling frame. Lists of these organisations have been obtained from the Ghanaian Embassy and the Association of Ghanaian Churches in the UK in the boroughs known to have the greatest concentration of Ghanaians. Lists of all members of their organisations, if available, have also been requested, from which a number of all participants aged $\geq 25$ years are invited to participate in the study. The selected participants receive a written invitation combined with written information regarding the study and a opting out response card. Participants are sent a confirmation letter of the appointment for a physical examination at a local health centre, church or community centre, including a digital or paper version of the questionnaire (depending on the preference of the participant) if they agreed to participate in the study.

\section{Recruitment strategy in Germany}

In Berlin, a list of Ghanaian individuals (born in Ghana, or Ghanaian passport holders) was provided by the registration office and that was supplemented with contact details of members of Ghanaian organisations and churches in Berlin. From this combined list, all participants aged $\geq 25$ years have been invited to participate in the study. In addition, a written invitation combined with written information regarding the study and a response card has been sent to the selected participants. Participants are reminded after 2 weeks if there is no response. After a positive response, the participants are contacted by phone to schedule date and location of the interview with a trained research assistant or opt for the digital online version. Subsequent to the completion of the questionnaire, a date for physical examination is then scheduled.

Informed written consent is also obtained from each participant prior to the enrolment in the study. In addition, an external independent Ethical advisor has been appointed by the RODAM Steering Committee to oversee the ethical issues in the RODAM study.

\section{Power and data analysis}

In the presented study, we aim to sample 6250 individuals comprising five subgroups of 1250 each from the five locations. For phenotypic, genetic and epigenetic studies, subsets are selected. In order to estimate the statistical power with regard to different sample sizes in the three types of data, we evaluated three distinct types of statistical power calculations with regard to the type of survey.

Phenotypic association: For the phenotypic association analysis, we assumed a prevalence of T2D of $<5 \%$ in rural Ghana, 6-7\% in urban Ghana and $>12 \%$ in Europe. $^{32} 39$ For obesity, we assumed a prevalence of $<5 \%$ in rural Ghana, $17 \%$ in urban Ghana and $30 \%$ in Europe. $^{2}{ }^{39}$ In general, we aim for a power of 0.90 with $\alpha=0.05$ (including Bonferroni correction). Using these parameters a sample size of approximately 1230 is needed in the rural Ghana, urban Ghana, Amsterdam, London and Berlin subsets to detect a difference between the group proportions of 5\%. T2D was defined as fasting plasma glucose $\geq 7 \mathrm{mmol} / \mathrm{L}$, or pre-existing antidiabetic medication or glycated haemoglobin (HbA1c) $\geq 6.5 \% .^{40}$ Generalised obesity was defined as body mass index $(\mathrm{BMI}) \geq 30 \mathrm{~kg} / \mathrm{m}^{2}$, and central obesity as a waist circumstance $>102 \mathrm{~cm}$ in men or $>88 \mathrm{~cm}$ in women. ${ }^{41} 42$

Genetic association: The present study aims to genotype a substantial part of the total sample among patients with diabetes (cases) and non-diabetes (controls). The genotyping will be based on a standard single nucleotide polymorphism array platform suitable for performing genome-wide association study as well as candidate gene analysis or related approaches. Using the statistical power calculator on binary traits for a casecontrol study design (S Purcell; http://pngu.mgh. harvard.edu/), assuming an allele frequency of 0.25 , a prevalence of $16 \%$, a relative risk of 1.3 and 1.6 (Aa and AA rep.), a D' of 1, the number of cases of 1000 (1:2 case-control ratio) and a type I error rate of 0.05 , approximately 540 cases are considered sufficient to obtain a power of 0.90 . Although the latter necessary sample size is covered by our study, it should be noted that correction for multiple tests, that is, if more than one genetic variant is tested, is not considered here. Nevertheless, candidate gene or related association approaches within this single study setup have sufficient statistical power to detect moderate and low effect sizes.

Epigenetic association: To explore the influence of epigenetic factors on the main outcomes, we will first assess the differences in methylation levels among Ghanaians living in rural and urban Ghana and Europe and their relative contributions to the differences to obesity and T2D that may be observed. With a study power of 0.80 and $\alpha=0.05$ (and $\mathrm{SD} \pm 0.10 \%$ ), at least 64 people per group are needed to detect a mean percentage difference in methylation density of $5 \%$. When multiple correction is taken into account, about 300 individuals per group of participants are needed. Epigenome-wide analysis will be performed. Association analysis of the DNA methylation profiles and obesity and T2D and related phenotypes will subsequently be performed. Promising loci will then be validated using nextgeneration bisulfite sequencing. 
Simple tables, proportions, mean and median values will be used to examine the data. Multivariable linear and logistics regression analyses will be used to assess the differences and to identify specific relevant factors and their relative contribution to the differences in body indices and fasting glucose (continuous and binary traits) between Ghanaian migrants and non-migrants.

\section{Data collection}

Data collection is composed of questionnaire/interviews, physical examination and biological samples. The methods for data collection in RODAM are identical in all locations following standard operating procedures and applying standardised tools. Questionnaires have been adapted to the local circumstances in Ghana, the Netherlands, the UK and Germany, where needed. For example, for all sites, modification of questions with respect to educational system or social security system was made. Before data collection, a 2-day training course in the Netherlands was organised for all those involved in data collection, on the overall project's procedures. The training involved the administration of the different questionnaires, physical examinations, processing of blood and urine samples in the laboratory and transport and storage of samples. The work package leaders, in turn, train all recruitment team members in each site on all aspects of the study. Interviewers are recruited among Ghanaian-speaking residents in Europe, are introduced to the aims and procedures of the study and are instructed and trained on the use of the questionnaires. Research assistants also receive the online tutorial for the Oracle Clinical data entry system. The performance of each interviewer or research assistant is monitored during the initial interviews and physical examinations. Feedback is provided and changes were initiated if needed. The RODAM coordinator monitors data collection at all study sites to ensure standardisation of methods.

\section{Questionnaire/interviews}

All the participants who agree to participate in the study receive an appointment for a structured interview. The interviews are conducted by trained interviewers of Ghanaian background and last for about 60-120 min. To increase participation rate, the participants are given a range of options including interviews in participants' homes and digital or paper version of the questionnaire, depending on the preference of the participant. The interviewers conduct the interviews in the preferred language of the respondent either in English, German, Dutch or Ghanaian languages. The interview is based on a structured health questionnaire, and contains questions on demographics (age, sex, marital status, household composition, religion), socioeconomic position (education level and parental education, employment status and parental employment status, occupational status and wealth), migration-related factors (premigration history, age at first migration, age at arrival in the current location, duration of residence, cultural distance and ethnic identity), psychosocial vulnerability (perceived discrimination, social support, mastery, recent negative life events and current depression), health status (self-reported general health and presence and history of diseases, family history of diseases), and health behaviour (eg, dietary behaviour, physical activity, alcohol and smoking, perceived body weight and body shape and adherence to medications) by using appropriate validated instruments (table 1 ). For example, physical activity is measured using the WHO Global Physical Activity Questionnaire (GPAQ) V.2. ${ }^{43}$ Dietary behaviour is determined by a Food Propensity Questionnaire (FPQ), specifically developed in RODAM to include Ghana-specific foods. In addition, a $24 \mathrm{~h}$ dietary recall questionnaire will be administered to a subset of the study population in each site $\left(n=5^{*} 100\right)$.

All participants who complete the questionnaire are invited for physical examination in the local research clinic or in a health centre. At the start of the visit, the study and the procedures involved are explained to each participant and informed consent is signed if not already carried out so at home.

After informed consent is given, physical measurements are made and biological samples, fasting blood and urine samples are collected.

\section{Physical measurements}

Physical examinations are performed with validated devices according to standardised operational procedures. Physical examinations comprise assessment of anthropometrics (weight, height, trunk, waist circumference and hip circumference), Bioimpedance Analysis (BIA), blood pressure and Ankle-Brachial Index (ABI) measures (table 2). The portable stadiometer SECA 217 is used for height measurement, the SECA 877 for weight measurement, measuring tape for abdominal and hip circumference and BODYSTAT 1500 MDD analyser for BIA. Blood pressure is measured three times using validated semiautomated device (The Microlife WatchBP home) with appropriate cuffs in a sitting position after at least 5 min rest. ABI is measured with The Microlife WatchBP Office ABI with appropriate cuffs in a supine position after at least 10 min rest. Each participant receives a summary of his/her main results accompanied by an explanation and the recommendation to contact his/her GP if the results are abnormal.

\section{Biological material \\ Blood samples}

Fasting venous blood samples are collected by trained research assistants in all sites. All blood samples are manually processed and aliquoted immediately after collection by a trained technician or research assistant according to standard operational procedures, and then temporarily stored at the local research location. Immediate processing and cryopreservation at the research location has the advantage of preserving any 
Table 1 Variables measured in the RODAM questionnaire

\begin{tabular}{|c|c|c|}
\hline Themes & Variable/measure & Questionnaire instrument/measures \\
\hline $\begin{array}{l}\text { Demographics } \\
\text { Socioeconomic } \\
\text { status }\end{array}$ & $\begin{array}{l}\text { Age, sex, marital status, religion, tribe, locality } \\
\text { 1. Education } \\
\text { 2. Employment status } \\
\text { 3. Wealth } \\
\text { 4. Parental socioeconomic status }\end{array}$ & $\begin{array}{l}\text { 1. Education attainment } \\
\text { 2. Nature of work } \\
\text { 3. Household index; wealth index (only in } \\
\text { Ghana) } \\
\text { 4. Father's and mother's education } \\
\text { attainment and profession }\end{array}$ \\
\hline $\begin{array}{l}\text { Migration-related } \\
\text { factors }\end{array}$ & $\begin{array}{l}\text { Generation, duration of residence in Europe, religion, } \\
\text { cultural distance, migration history }\end{array}$ & - \\
\hline Health status & $\begin{array}{l}\text { 1. General health } \\
\text { 2. Presence and history of diseases and family history } \\
\text { of diseases }\end{array}$ & $\begin{array}{l}\text { 1. } \mathrm{SF}-12^{44} \\
\text { 2. Various health conditions }\end{array}$ \\
\hline Psychosocial factors & $\begin{array}{l}\text { 1. Perceived discrimination } \\
\text { 2. Perceived social support } \\
\text { 3. Dealing with everyday problems } \\
\text { 4. Recent experiences (stressful life events) } \\
\text { 5. Psychological stress } \\
\text { 6. Recent well-being }\end{array}$ & $\begin{array}{l}\text { 1. Everyday Discrimination Scale }{ }^{45} \\
\text { 2. SSQT Satisfaction Emotional Support } \\
\text { subscale }^{46} \\
\text { 3. Mastery } \\
\text { 4. List of threatening experiences } \\
\text { 5. } 2 \text { items from INTERHEART } \\
\text { 6. Patient Health Questionnaire- } 9^{50}\end{array}$ \\
\hline Health behaviour & $\begin{array}{l}\text { 1. Smoking } \\
\text { 2. Alcohol intake } \\
\text { 3. Physical activity } \\
\text { 4. Dietary behaviour } \\
\text { 5. Perceived body weight and body shape } \\
\text { 6. Adherence to medication }\end{array}$ & $\begin{array}{l}\text { 1. - } \\
\text { 2. - } \\
\text { 3. WHO GPAQ V. } 2^{43} \\
\text { 4. Ghana-specific FPQ, 24-h dietary recalls } \\
\text { for subsample }\left(n=5^{\star} 100\right) \\
\text { 5. Pulvers instrument to measure body } \\
\text { image }^{51} \\
\text { 6. Self-reported adherence }{ }^{52}\end{array}$ \\
\hline
\end{tabular}

highly labile molecules in the samples. Standardised procedures ensure that each sample is collected, handled, processed, transported and stored in the same way across the sites. The samples are then transported to the respective local laboratories (Durrer Center for Cardiogenetic Research at the AMC, Amsterdam; Kwame Nkrumah University of Science and Technology, KCCR, Kumasi, Faculty of Infectious and Tropical Diseases, LSHTM, London \& Institute of Tropical Medicine and International Health, Berlin), where samples are checked, registered and stored at $-80^{\circ} \mathrm{C}$. These samples include EDTA whole blood, heparin plasma and serum. In addition, on the spot, fasting plasma glucose level is assessed by validated hand-held device (Accu-Chek Performa metre+Accu-Chek Inform II test strip (Roche, Germany) in all sites to provide accurate glucose determination as blood glucose concentration tends to decline over time in blood samples. ${ }^{53}$

\section{Morning urine sample}

Participants are asked to bring the first early morning urine in a clean jar. The urine sample is tested with a

Table 2 Physical examination variables measured in RODAM

\begin{tabular}{lll}
\hline Themes & Measures & Instrument \\
\hline Anthropometrics & 1. Weight & 1. SECA 877 \\
& 2. Height and trunk & 2. SECA 217 \\
& 3. Waist circumference & 3. Measuring tape \\
& 4. Hip circumference & 4. Measuring tape \\
5. Body fat (Bio Impedance Analysis) & 5. BODYSTAT 1500 MDD analyser for BIA \\
Blood pressure & Systolic and diastolic blood pressure, measured & The Microlife WatchBP home \\
Ankle-Brachial Index & 3 times in a sitting position after at least 5 min rest & The Microlife WatchBP Office ABI \\
& Ankle-Brachial Index, measured in a supine & \\
\hline RODAM, Research on Obesity and Diabetes among African Migrants. &
\end{tabular}

3. Measuring tape

4. Measuring tape

5. BODYSTAT $1500 \mathrm{MDD}$ analyser for BIA

The Microlife WatchBP Office ABI 
dipstick in the Urysis 1100 (Combur 7, Roche) on the spot, to determine $\mathrm{pH}$, glucose, ketones, leucocytes, nitrite, protein and erythrocytes. One sample per participant is transported, together with the blood samples, to the respective local laboratory and stored at $-80^{\circ} \mathrm{C}$.

\section{Transfer of biological material to dedicated centres for biochemical analyses and genotyping}

From the local research centres, the two aliquoted samples, one urine sample and a $2 \mathrm{~mL}$ EDTA are then transported to Berlin for biochemical analyses including glucose metabolism (fasting glucose, HbAlc, insulin), lipid profile (total cholesterol, high-density lipoprotein cholesterol, low-density lipoprotein cholesterol and triglycerides), electrolytes and renal function (creatinine, albumin, sodium, potassium, calcium), uric acid metabolism (uric acid), liver metabolism (alanine transaminase, aspartate aminotransferase, $\gamma$-glutamyl transpeptidase), oxidative status and iron metabolism (ferritin) and inflammation (high-sensitivity $\mathrm{C}$ reactive protein); and a $4 \mathrm{~mL}$ EDTA whole blood sample is transported to Nottingham for DNA extraction and genotyping. Shipping of the samples from European sites is carried out using styrofoam boxes filled with dry ice and from Ghana in dry shippers filled with liquid nitrogen. Numerous factors including temperature, packaging, courier, sample type, import/export requirements, seasons, costs and transit time/ship days can affect biological specimen integrity during transportation domestically and internationally. Hence, staff involved with shipping the specimens have been trained in order to minimise factors that might affect the integrity of the specimens. In addition, training regarding legal or regulatory aspects of shipment of specimens such as Material Transfer Agreement (MTA) has been given. Each centre maintains a shipment log to record the receipt and dissemination of shipments sent from the centre. Each shipment entry is given a unique shipment number.

\section{Qualitative interviews of perception and knowledge of obesity and T2D}

Interventions to reduce obesity and T2D have often been ineffective particularly in migrant populations. ${ }^{28}$ This may, in part, relate to poor perceptions and knowledge about both conditions. Access to preventive and curative services may depend on a wide range of factors including knowledge of services and how to use them, health beliefs and attitudes, language barriers, the sensitivity of services to differing needs and the quality of care provided. Gaining in-depth insight into these factors requires qualitative methodology. Thirty-two individual interviews with people with diabetes and eight focus groups (including up to eight participants per group) with lay healthy individuals will be held at each location. Segmentation categories for purposive sampling for people with diabetes are gender, duration of diabetes, BMI status and age. Each individual interview and focus group interview is conducted by trained interviewers using the same themes across all sites and had duration of 60-90 min. Interviews are recorded, transcribed and analysed using qualitative data software. A coding framework of themes is developed based on the RODAM theoretical framework and social representations theory. ${ }^{54}$ Coding is carried out inductively and deductively through a constant comparative approach. All transcripts are coded separately by two independent researchers and are systematically discussed and compared for inter-rater reliability.

\section{Current status of the study}

The RODAM project study is currently enrolling participants from five localities in four countries. As of January 2014, we have examined and interviewed 3868 participants (rural $\mathrm{n}=1057$, urban Ghana $\mathrm{n}=863$, Amsterdam $\mathrm{n}=1011$, London $\mathrm{n}=597$ and Berlin $\mathrm{n}=340$ ) who fulfilled the RODAM eligibility criteria. Blood and urine samples from these participants have been stored at the local sites in Ghana, Amsterdam, London and Berlin. Part of these samples have been successfully shipped from the study sites to Charité-Universitätsmedizin Berlin for biochemical analyses, and to Source Bioscience in Nottingham for DNA extraction. Genotyping will start once all the data collection is completed. The data collection for the qualitative part of the project is ongoing in rural and urban Ghana, Amsterdam and London. Database has been built and the outline of the data storage structure has been defined. The data analysis will begin once the data cleaning is completed.

\section{DISCUSSION}

SSA migrants to Europe belong to one of the fastest growing migrant groups in Europe today. ${ }^{56}$ The unprecedented high levels of CVDs and related risk factors, such as obesity and T2D, have huge clinical care and public health implications. Consequently, the need to get detailed insights into the possible underlying determinants of obesity and T2D and related complications to help support the preventive efforts as well as clinical management is increasingly being recognised. This is particularly so in major European cities where some of these populations form a major part of the patient population. ${ }^{31}$ Simultaneously, African countries are facing huge challenges regarding obesity and T2D and related complications. ${ }^{79}$ This issue was recently highlighted in the meeting of the general assembly of the United Nations on Non-Communicable Diseases in 2011 as an important epidemic of our times (http://www.un.org/en/ $\mathrm{ga} /$ president/65/issues/ncdiseases.shtml). Unfortunately, the established health education and lifestyle interventions mainly in the European host populations may not be applied in migrant populations and other world regions such as Africa because of differences in susceptibility, nutrition, social circumstances and culture. Still, in Africa and among African migrants, data are highly fragmentary and based on heterogeneous populations. Consequently, the magnitude of the problem is uncertain and the relative 
contribution of risk factors is undefined. Thus, it is difficult to set rational priorities for targeted health interventions and policies and to monitor progress towards set goals. Knowledge on health-related outcomes that are directly associated with the migration process will allow for the most effective and appropriate use of interventions, efforts and investments to improve and promote the health of these populations. $^{51}$

Comparative studies such as RODAM have an enormous potential for migrant populations and for the countries from which they have migrated from. For migrant populations, it provides indications of how exposure to different environmental circumstances might influence health outcomes. This is highly relevant in that the industrialised countries themselves differ greatly in terms of opportunities for socioeconomic development of the migrant groups, race relations and access to healthcare and preventive services. ${ }^{57}$ These differential contexts can undoubtedly influence health behaviour and healthcare use among migrant groups, and subsequently lead to differences in health outcomes between similar migrant populations living in different countries. ${ }^{30}{ }^{32}$ For the countries of origin, the rapid increases of obesity and T2D following migration to high-income countries give a clear indication of the vulnerability of the population left behind as many of these countries continue to westernise. ${ }^{57}$

The high prevalence of obesity and T2D among migrant groups obviously is a result of a multitude of different factors. Thorough understanding of the factors is a prerequisite for efficient intervention and prevention. The rigorous characterisation of biochemical parameters and specific environmental factors as well as epigenetic factors will allow comparing the major pathophysiological aspects of obesity and T2D between African migrants and their compatriots who did not migrate. Epigenetic data have a huge potential to point to, as yet, unrecognised pathophysiological pathways in obesity and T2D, and thus reveal options for improved diagnosis and treatment.

The RODAM project will deliver up-to-date data on obesity and T2D among SSA migrants in Europe and their home country. This will allow us to draw conclusions on the magnitude of the problem and deduce the attributable risk of migration from rural to urban environment as well as migration to Europe for obesity and T2D. Our findings on the influence of migration (from Africa to Europe) will help healthcare providers and health policy stakeholders to better understand and predict comparable developments in other African populations and in other parts of the world; and to (re) direct efforts to the most obvious changes induced by migration that affect obesity and diabetes.

\footnotetext{
Author affiliations

${ }^{1}$ Department of Public Health, Academic Medical Centre (AMC), University of Amsterdam, Amsterdam, The Netherlands

${ }^{2}$ Faculty of Science, Kwame Nkrumah University of Science and Technology, Kumasi, Ghana

${ }^{3}$ The Regional Institute for Population Studies: University of Ghana, Legon, Ghana
}

${ }^{4}$ Department of Non-communicable Disease Epidemiology, London School of Hygiene and Tropical Medicine, London, UK

${ }^{5}$ Institute of Tropical Medicine and International Health, CharitéUniversitätsmedizin Berlin, Berlin, Germany

${ }^{6}$ Department of Molecular Epidemiology, German Institute of Human Nutrition (DlfE), Potsdam-Rehbruecke, Nuthetal, Germany

${ }^{7}$ Department of Endocrinology, Diabetes and Nutrition, Charité-

Universitätsmedizin Berlin, Berlin, Germany

${ }^{8}$ Julius Global Health, Julius Center for Health Sciences and Primary Care, University Medical Center, Utrecht, The Netherlands

${ }^{9}$ Division of Epidemiology and Biostatistics, School of Public Health, Faculty of Health Sciences, University of the Witwatersrand, Johannesburg,

South Africa

${ }^{10}$ Source BioScience, Nottingham, UK

${ }^{11}$ Department of Clinical Genetics, Academic Medical Centre, Amsterdam, The Netherlands

${ }^{12}$ Department of Clinical Chemistry, Academic Medical Centre, Amsterdam, The Netherlands

${ }^{13}$ International Diabetes Federation, Africa Region, Kampala, Uganda

${ }^{14}$ Department of Clinical Epidemiology, Bioinformatics, and Biostatistics, Academic Medical Centre, University of Amsterdam, Amsterdam, The Netherlands

Correction notice This article has been corrected since it was published Online First. The license has been change to $\mathrm{CC} B Y$ and the funding statement has been updated.

Acknowledgements The authors are very grateful to the advisory board members for their valuable support in shaping the methods, and to the Ghanaian volunteers participating in this project.

Contributors CA, EO-D, Ad-GA, LS, JA, FM, ID, MBS, JS, K-KG, SB, AH-Z, $A E K$ and $K S$ developed the original grant proposal. CA, EB and KM prepared the first draft with the support of all authors. All authors read and approved the final manuscript.

Funding This work is supported by the European Commission under the Framework Programme (grant number 278901). Professor Smeeth's contribution was supported by the Wellcome Trust, grant number WT082178.

Competing interests None.

Patient consent Obtained.

Ethics approval Ethical approval of the study protocols has been requested at all sites from the respective ethics committees in Ghana (School of Medical Sciences/Komfo Anokye Teaching Hospital Committee on Human Research, Publication \& Ethical Review Board), the Netherlands (Institutional Review Board of the AMC, University of Amsterdam), Germany (Ethics Committee of Charite-Universitätsmedizin Berlin) and the UK (London School of Hygiene and Tropical Medicine Research Ethics Committee) before data collection began in each country

Provenance and peer review Not commissioned; peer reviewed for ethical and funding approval prior to submission.

Open Access This is an Open Access article distributed in accordance with the terms of the Creative Commons Attribution (CC BY 3.0) license, which permits others to distribute, remix, adapt and build upon this work, for commercial use, provided the original work is properly cited. See: http:// creativecommons.org/licenses/by/3.0/

\section{REFERENCES}

1. Misra A, Ganda OP. Migration and its impact on adiposity and type 2 diabetes. Nutrition 2007;23:696-708.

2. Agyemang $\mathrm{C}$, Owusu-Dabo $\mathrm{E}$, de Jonge $\mathrm{A}$, et al. Overweight and obesity among Ghanaian residents in the Netherlands: how do they weigh against their urban and rural counterparts in Ghana? Public Health Nutr 2009;12:909-16.

3. Agyemang C, Addo J, Bhopal R, et al. Cardiovascular disease, diabetes and established risk factors among populations of sub-Saharan African descent in Europe: a literature review. Global Health 2009;5:7. 
4. Oldroyd J, Banerjee M, Heald A, et al. Diabetes and ethnic minorities. Postgrad Med J 2005;81:486-90.

5. Gill PS, Kai J, Bhopal RS, et al. Health care needs assessment: black and minority ethnic groups. In: Raftery J, ed. Health care needs assessment. The epidemiologically based needs assessment reviews. Third Series. Abingdon: Radcliffe Medical Press Ltd, 2006:227-39.

6. Health Survey for England 2004: Health of Ethnic Minorities. http://www.ic. nhs.uk/webfiles/publications/hlthsvyeng2004ethnic/HealthSurveyFor England161205_PDF\%20.pdf

7. Abubakari AR, Bhopal RS. Systematic review on the prevalence of diabetes, overweight/obesity and physical inactivity in Ghanaians and Nigerians. Public Health 2008;122:173-82.

8. Amoah AG, Owusu SK, Adjei S. Diabetes in Ghana: a community based prevalence study in Greater Accra. Diabetes Res Clin Pract 2002;56:197-205.

9. Abubakari AR, Lauder W, Agyemang C, et al. Prevalence and time trends in obesity among adult West African populations: a meta-analysis. Obes Rev 2008;9:297-311.

10. Amoah AG. Sociodemographic variations in obesity among Ghanaian adults. Public Health Nutr 2003;6:751-7.

11. International Diabetes Federation. Diabetes atlas. 5th edn. Brussels: International Diabetes Federation, 2011.

12. Hossain P, Kawar B, El Nahas M. Obesity and diabetes in the developing world - a growing challenge. N Engl J Med 2007;356:213-15.

13. Karter AJ, Ferrara A, Liu JY, et al. Ethnic disparities in diabetic complications in an insured population. JAMA 2002;287:2519-27.

14. Staiger $\mathrm{H}$, Machicao $\mathrm{F}$, Fritsche $\mathrm{A}$, et al. Pathomechanisms of type 2 diabetes genes. Endocr Rev 2009;30:557-85.

15. Freeman H, Cox RD. Type-2 diabetes: a cocktail of genetic discovery. Hum Mol Genet 2006;15:202-9.

16. Warner MJ, Ozanne SE. Mechanisms involved in the developmenta programming of adulthood disease. Biochem J 2010;427:333-47.

17. Hales CN, Barker DJ. Type 2 (non-insulin-dependent) diabetes mellitus: the thrifty phenotype hypothesis. Diabetologia 1992;35:595-601.

18. Van Speybroeck $L$. From epigenesis to epigenetics: the case of C. H. Waddington. Ann N Y Acad Sci 2002;981:61-81.

19. Plagemann A, Harder T, Brunn M, et al. Hypothalamic POMC promoter methylation becomes altered by early overfeeding: an epigenetic model of obesity and the metabolic syndrome. J Physiol 2009;587(Pt 20):4963-76.

20. Prentice AM. Early influences on human energy regulation: thrifty genotypes and thrifty phenotypes. Physiol Behav 2005;86:640-5.

21. Tobi EW, Lumey LH, Talens RP, et al. DANN methylation differences after exposure to prenatal famine are common and timing- and sex-specific. Hum Mol Genet 2009;18:4046-53.

22. Rock M. Sweet blood and social suffering: rethinking cause-effect relationships in diabetes, distress and suress. Med Anthropol 2003;22:131-74.

23. Manson JE, Nathan DM, Krolewski AS, et al. A prospective study of exercise and incidence of diabetes among US male physicians. JAMA 1992;268:63-7.

24. Williamson DF, Madans J, Anda RF, et al. Recreational physical activity and ten-year weight change in a US national cohort. Int $J$ Obes Relat Metab Disord 1993;17:279.

25. Hamman RF. Genetic and environmental determinants of non-insulin-dependent diabetes mellitus (NIDDM). Diabetes Metab Rev 1992;8:287-338.

26. Miller WC, Koceja DM, Hamilton EJ. A meta-analysis of the past 25 years of weight loss research using diet, exercise or diet plus exercise intervention. Int J Obes Relat Metab Disord 1997;21:941-7.

27. Tuomilehto J, Lindström J, Eriksson JG, et al. Finnish Diabetes Prevention Study Group. Prevention of type 2 diabetes mellitus by changes in lifestyle among subjects with impaired glucose tolerance. N Engl J Med 2001;344:1343-50.

28. Uitewaal PJ, Voorham AJ, Bruijnzeels MA, et al. No clear effect of diabetes education on glycaemic control for Turkish type 2 diabetes patients: a controlled experiment in general practice. Neth $\mathrm{J}$ Med 2005;63:428-34.

29. Scott P, Rajan L. Eating habits and reactions to dietary advice among two generations of Caribbean people: a South London study, part 2. Pract Diabetes Int 2000;17:213-16.

30. Agyemang $C$, Kunst $A E$, Stronks K. Ethnic inequalities in health: does it matter where you have migrated to? Ethn Health 2010;15:216-18.

31. Fernades A, Miguel JP. Health and migration in the European union: better health for all in an inclusive society. Lisbon: Instituto Nacional de Saúde Doutor Ricardo Jorge, 2009.

32. Agyemang $\mathrm{C}$, Kunst $\mathrm{AE}$, Bhopal $\mathrm{R}$, et al. Diabetes prevalence in populations of South Asian Indian and African origins: a comparison of England and the Netherlands. Epidemiology 2011;22:563-7.
33. World Health Organization. Health of migrants - the way forward. Report of a global consultation. Madrid: World Health Organization, 2010.

34. Office for National Statistics. Estimated population resident in the United Kingdom, by foreign country of birth (Table 1.3). London: ONS, 2009.

35. German Technical Cooperation (GTZ). Die ghanaische Diaspora in Deutschland-Ihr Beitrag zur Entwicklung Ghanas. Eschborn: GTZ, 2009.

36. Central Bureau for Statistics. Statistical yearbook 2009. Statistics Netherlands Facility Services. The Hague: Henri Faasdreef 312, 2492 JP, 2009.

37. Elam G, Chinouya M, Nazroo J. Feasibility study for health surveys among black African people living in England Final reportimplications for the Health Survey for England 2003. London: Joint Health Surveys Unit National Centre for Social Research, 2001.

38. Agyemang C, Nicolaou M, Boateng L, et al. Prevalence, awareness, treatment, and control of hypertension among Ghanaian population in Amsterdam, the Netherlands: the GHAIA study. Eur J Prev Cardiol 2013;20:938-46.

39. Nicolaou M, Kunst AE, Busschers WB, et al. Differences in body fat distribution play a role in the lower levels of elevated fasting glucose amongst Ghanaian migrant women compared to men. PLOS ONE 2013:8:e66516.

40. American Diabetes Association. Diagnosis and classification of diabetes mellitus. Diabetes Care 2010;33(Suppl 1):S62-9.

41. WHO. Obesity: preventing and managing the global epidemic. Report of a WHO consultation. World Health Organ Tech Rep Ser, 2000;894:i.

42. National Institutes of Health, National Heart, Lung, and Blood Institute. Clinical guidelines on the identification, evaluation, and treatment of overweight and obesity in adults-the evidence report. National Institutes of Health. Obes Res 1998;(6 Suppl 2):51S.

43. Bull FC, Maslin TS, Armstrong T. Global physical activity questionnaire (GPAQ): nine country reliability and validity study. $J$ Phys Act Health 2009;6:790-804.

44. Larson CO, Schlundt D, Patel K, et al. Validity of the SF-12 for use in a low-income African American community-based research initiative (REACH 2010). Prev Chronic Dis 2008;5:A44.

45. Williams DR, Yan Yu, Jackson JS, et al. Racial differences in physical and mental health: socio-economic status, stress and discrimination. J Health Psychol 1997;2:335-51.

46. Suurmeijer TP, Doeglas DM, Briançon S, et al. The measurement of social support in the 'European Research on Incapacitating Diseases and Social Support': the development of the Social Support Questionnaire for Transactions (SSQT). Soc Sci Med 1995;40:1221-9.

47. Pearlin LI, Schooler C. The structure of coping. J Health Soc Behav 1978;19:2-21.

48. Brugha TS, Cragg D. The list of threatening experiences: the reliability and validity of a brief life events questionnaire. Acta Psychiatr Scand 1990;82:77-81.

49. Yusuf $S$, Hawken S, Ounpuu S, et al. INTERHEART Study Investigators. Effect of potentially modifiable risk factors associated with myocardial infarction in 52 countries (the INTERHEART study): case-control study. Lancet 2004;364:937-52.

50. Kroenke K, Spitzer RL, Williams JB, et al. The Patient Health Questionnaire Somatic, Anxiety and Depressive Symptom Scales: a systematic review. Gen Hosp Psychiatry 2010; 32:3445-359.

51. Pulvers KM, Lee RE, Kaur $\mathrm{H}$, et al. Development of a culturally relevant body image instrument among urban African Americans. Obes Res 2004;12:1641-51.

52. Nieuwkerk PT, de Boer-van der Kolk IM, Prins JM, et al. Self-reported adherence is more predictive of virological treatment response among patients with a lower tendency towards socially desirable responding. Antivir Ther 2010;15:913-16.

53. Chan A, Cockram C, Swaminathan R. Effect of delay in separating plasma for glucose measurement upon the interpretation of oral glucose tolerance tests. Ann Clin Biochem 1990;27:73-4.

54. Moscovici S. The phenomenon of social representations. In: Farr RMMoscovici S, eds. Social representations. Cambridge: Cambridge University Press, 1984:3-70

55. de-Graft Aikins A. Healer-shopping in Africa: new evidence from a rural-urban qualitative study of Ghanaian diabetes experiences. BMJ 2005;331:737.

56. Organization for Economic Cooperation and Development. Table A.1.1. Inflows of foreign population into selected OECD countries. International Migration Outlook. Sopemi, 2006.

57. Agyemang C, de-Graft Aikins A, Bhopal R. Ethnicity and cardiovascular health research: pushing the boundaries by including comparison populations in the countries of origin. Ethn Health 2012;17:579-96. 


\section{Correction}

Agyemang C, Beune E, Meeks K, et al. Rationale and cross-sectional study design of the Research on Obesity and type 2 Diabetes among African Migrants: the RODAM study. BMJ Open 2014;4:e004877. This paper was published under an incorrect license. The correct open access license is CC BY:

Open Access This is an Open Access article distributed in accordance with the terms of the Creative Commons Attribution (CC BY 3.0) license, which permits others to distribute, remix, adapt and build upon this work, for commercial use, provided the original work is properly cited. See: http://creativecommons.org/licenses/by/3.0/

The amended funding statement is:

Funding This work is supported by the European Commission under the Framework Programme (grant number 278901). Professor Smeeth's contribution was supported by the Wellcome Trust, grant number WT082178.

The corrected article is available online.

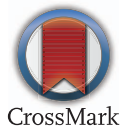

BMJ Open 2015;5:e004877. doi:10.1136/bmjopen-2014-004877corr1 